\title{
BOBBIO Y EL HOLOCAUSTO Un capítulo de su reflexión sobre los derechos humanos: el texto "Quindici anni dopo" y sus desdoblamientos
}

\author{
Celso Lafer \\ Universidad de San Pablo
}

\begin{abstract}
RESUMEN. El autor trata de rescatar la importancia de uno de los textos menos conocidos y de más difícil acceso de Norberto Bobbio: "Quindici anni dopo", texto que contiene el discurso que Bobbio pronunció en la sinagoga de Turín el 10 de enero de 1960, como muestra de solidaridad con la comunidad judía. En "Quindici anni dopo" Bobbio aborda "el problema del mal" o "el horror y la perplejidad ante la descartabilidad del ser humano engendrada por el racismo del totalitarismo nazi”. El Holocausto, el mayor crimen conocido, plantea al pensamiento del filósofo italiano varias interrogantes: la ausencia de referentes para contrastar el genocidio organizado, cuyo único fin -a diferencia de la guerra, por ejemplo- es el exterminio; la dificultad de explicar el genocidio con las categorías tradicionales del pensamiento, debido a su gratuidad, a la imposibilidad de clasificarlo entre los motivos humanos corrientes y a no ser el producto de un estado de excepción; y la naturaleza del prejuicio y el racismo.
\end{abstract}

\begin{abstract}
The author seeks to recuperate the importance of one of Norberto Bobbio's least known and most inaccessible texts: "Quindici anni dopo", which contains the speech made by Bobbio, as a token of his solidarity with the jewish community, in Turin synagogue on January 10th, 1960. In "Quindici anni dopo" Bobbio deals with "the problem of evil" or "the horror and the perplexity when faced with the negation of the human being brought about by the racism of nazi totalitarianism". The Holocaust, the greatest known crime, presents the Italian philosopher's thinking with a number of questions: the absence of references with which to compare organized genocide which, unlike war, for example, has only one end, extermination; the difficulty when seeking to explain genocide using the traditional categories of thought, because it is gratuitous, because it is impossible to classify among the usual human motives and because of the fact that it is not the product of a state of emergency; and because of the nature of prejudice and racism.
\end{abstract}




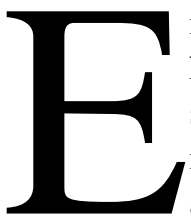
n el recorrido intelectual de Norberto Bobbio los derechos humanos son un tema de primera importancia. En su reflexión se valió del método de las aproximaciones sucesivas y, de manera multidisciplinar, de los conceptos de los distintos campos a los que se dedicó. Por esta razón, en sus estudios convergen explícitamente el gran teórico del Derecho, de la política y de las relaciones internacionales, sin que falte además el intelectual militante que se dedicó a salvaguardar la cultura de los fanatismos políticos.

En L'età dei diritti Bobbio destaca, a la manera de Kant, que uno de las signos positivos de nuestro tiempo es la importancia creciente que se atribuye al reconocimiento de los derechos humanos. Este reconocimiento es producto del refuerzo mutuo de los procesos históricos de positivación, generalización, internacionalización y especificación de la tutela jurídica de los derechos humanos. El hito inicial de la afirmación universal y positiva de los derechos humanos fue la Declaración de 1948, que incluyó los derechos humanos en la agenda internacional como un tema global. Para Bobbio, el antecedente conceptual de esta dimensión extensiva es el kantiano jus cosmopoliticum, que anticipaba el momento en que la violación del Derecho ocurrida en una parte de la tierra sería sentida en todas las demás. En la discusión del proceso de especificación, Bobbio observa que se trata de una profundización de la tutela que deja de tomar en cuenta sólo a los destinatarios genéricos -el ser humano, el ciudadano-, objeto del proceso de generalización, para ocuparse del ser en situaciones concretas. Uno de los ejemplos que da de la especificación en el plano internacional es la Convención de la ONU de 1965 para la eliminación de todas las formas de discriminación racial. Bobbio también hace hincapié en la importancia de la Convención para la prevención y represión del crimen de genocidio de 1948, que extiende a un grupo humano considerado en su conjunto el alcance de los artículos 3, 4 y 5 de la Declaración Universal con rigor de tutela penal.

La conversión de los derechos humanos en un tema global y no limitado -el proceso de la internacionalización- y algunas relevantes facetas del proceso de especificación, son el resultado de una política del Derecho cuya fuente material fue la sensibilidad axiológica del horror erga omnes frente al mal de la descartabilidad del ser humano, producto de lo inédito de la violencia del racismo nazi que condujo al Holocausto. Auschwitz, dice Bobbio, es uno de los acontecimientos que impone una discusión sobre el problema del mal, que él examina en Elogio della mitezza e altri scritti morali, en sus dos vertientes: el mal activo, infligido por la violencia prepotente y sin límites del poder, y el mal pasivo, sufrido por aquellos que padecen un daño sin culpa. Bobbio discute también en Elogio della mitezza la naturaleza 
del prejuicio y del racismo, de su fenomenología y sus ideologías, y señala que la forma más persistente de racismo conocida por los europeos es el antisemitismo.

Señalo las muy conocidas reflexiones de Bobbio ${ }^{1}$ porque creo que tienen un importante antecedente que las ilumina y complementa. Me refiero al texto "Quindici anni dopo" y sus desdoblamientos, que tocaré en esta mesa redonda en su homenaje.

“Quindici anni dopo" es el texto del discurso pronunciado por Bobbio en la sinagoga de Turín el 10 de enero de 1960, en una manifestación de solidaridad con la comunidad judía. Fue publicado en Risorgimento, $\mathrm{X}, \mathrm{n}^{\circ}$ 1, enero de 1960, p. 8-9, y vuelto a publicar en Rassegna mensile di Israel, junio de 1974. Figura en la entrada no 6007, p. 100-101, de la Bibliografia degli Scritti di Norberto Bobbio-1934-1993, organizada por Carlo Violi (Roma-Bari, Laterza, 1995) y no fue incluido posteriormente en antologías de ensayos de Bobbio.

Recibí la separata de la publicación de 1974 de "Quindici anni dopo" de manos del propio Bobbio tras el contacto personal que iniciamos con ocasión de su viaje a Brasil en 1982. En una carta que me envió desde Turín el 2 de octubre de 1982, a propósito de los temas que en aquella ocasión discutimos, uno de los cuales fue la obra de Hannah Arendt, escribió: "En estos días le he enviado dos paquetes de libros y separatas mías, que podrá eventualmente añadir al estante de su bibliteca que comprende las obras de N. B. Una curiosidad: encontará también una separata titulada Quindici anni dopo que recoge el discurso que hice en la sinagoga de Turín, por invitación de la Comunidad israelita de la ciudad, cuando quince años después de la guerra (en 1960) aparecieron las primeras esvásticas en las paredes de Turín (Fui encargado del discurso oficial en cuanto no judío)”.

"Quindici anni dopo" es un texto muy relevante en el que Bobbio trata del horror y de la perplejidad ante la descartabilidad del ser humano engendrada por el racismo del totalitarismo nazi. Fue este horror y esta perplejidad lo que impulsó la positivación en el plano internacional del “derecho a tener derechos”, por decirlo con las categorías de Hannah Arendt. Es en ese texto donde Bobbio discute el Holocausto con el rigor y la profundidad que

\footnotetext{
${ }^{1}$ Cf. Norberto Bobbio, L'età dei diritti, Turín, Einaudi, 1997, p. 23, 30, 32, 45, 46, 48, 62; Elogio della mitezza e altri scritti morali, Milán, Linea d’Ombra, 1994, p. 145, 196, 198-199 y passim.
} 
caracterizan su obra, en la cual incluso lo hablado es siempre "un hablar escrito y reescrito"2.

En este texto Bobbio considera el Holocausto como una de los grandes problemas de la política y de los derechos humanos del siglo XX. El genocidio premeditado y organizado, conducido por el régimn nazi, dice, “es un hecho único en la historia, el mayor delito hasta ahora cometido de unos hombres contra otros hombres”3. En este sentido, Bobbio, en 1960, anticipa la tesis que sostiene Hannah Arendt en Eichmann in Jerusalem, publicado en 1963 y revisado en 1964, de que el Holocausto es, por su naturaleza y escala, un crimen sin precedentes ni antecedentes ${ }^{4}$. Nada hay, recuerda Bobbio, que se compare con el genocidio organizado y premeditado: “entre el horror de la guerra y el horror del genocidio, aunque no hubiera una diferencia de cantidad (pero seis millones de muertos son una cantidad desmesurada), hay una diferencia de naturaleza: la guerra es la eterna lucha del hombre contra el hombre llevada a cabo con medios violentos, los hombres convertidos en lobos que se devoran entre sí; la guerra puede conducir incluso al exterminio, pero su fin es la victoria, no el exterminio. En el genocidio organizado y premeditado el exterminio ha sido fin en sí mismo" (cursiva mía) ${ }^{5}$.

Fue esto lo que llevó a la especificación de la Convención de la ONU para la prevención y represión del crimen de genocidio. Recuerdo que Bobbio reitera esta visión del genocidio también en un discurso pronunciado en la sinagoga de Turín el 13 de mayo de 1990, publicado inicialmente en el diario La Repubblica del 17 de mayo de 1990 con el título "I barbari dei Lager possono tornare...”6, por tanto, en el año de la publicación de la primera edición de L'età dei diritti.

\section{III}

De ahí deriva otra gran cuestión discutida por Bobbio y que puede considerarse que integra el tema arendtiano de la ruptura. En otras palabras, la dificultad de encontrar en las tradicionales categorías del pensamiento una explicación aceptable para el genocidio, que es uno de los componentes de lo inédito del totalitarismo.

${ }^{2}$ Cf. Norberto Bobbio, Pietro Polito, Il mestieri di vivere, il mestieri di insegnare, il mestieri di scrivere-A colloquio in occasione dei novant'anni di Norberto Bobbio, Nuova Antologia, Fasc. 2211, julio-setiembre 1999, p. 43.

${ }^{3}$ Norberto Bobbio, Quindici anni dopo, Rassegna mensile di Israel, junio 1974, p. 4.

${ }^{4}$ Cf. Celso Lafer, A Reconstrução dos Direitos Humanos, um diálogo com o pensamento de Hannah Arendt, San Pablo, Cia. das Letras, 1988, cap. VI.

${ }^{5}$ Norberto Bobbio, Quindici anni dopo, in loc. cit. p. 4.

${ }^{6}$ Cf. Bibliografia degli Scritti di Norberto Bobbio, 1934-1993, organizada por Carlo Violi, cit. entrada 9005. 
Me animo a hacer esta aproximación porque el tema de la ruptura es uno de los que traté en mi libro de 1988, A Reconstrução dos Direitos Humanos, um diálogo com o pensamento de Hannah Arendt, que Bobbio conocía y al que, para mi regocijo, se refirió con generosidad en L'età dei diritti' Dice Bobbio a propósito de la ruptura: "Una de las razones del horror que continúa suscitando en mí el genocidio nazi es que no tiene una explicación, quiero decir, una de esas explicaciones de las que habitualmente se sirven los historiadores para insertar un hecho en un contexto más general, como los intereses económicos, el deseo de poder, el prestigio nacional, los conflictos sociales, las luchas de clases, las ideologías... el no llegar a explicar su razón en términos de motivos humanos habituales nos lo hace más espantoso"».

Asimismo, Bobbio reitera este tema de la ruptura en el discurso antes mencionado del 13 de mayo de 1990 en la sinagoga de Turín, publicado en La Reppublica del 17 de mayo de 1990: "El genocidio de los judíos es un delito premeditado, ya anunciado en los escritos de los nazis, y escrupulosamente, científicamente ejecutado. Se destruye al enemigo para ganar la guerra. Pero la masacre de los judíos, ¿para qué debía servir? ¿para qué ha servido? En mis categorías de historiador y de hombre de razón no encuentro una respuesta a estas preguntas”.

Fue el esfuerzo de buscar una respuesta a estas cuestiones lo que llevó a Bobbio a ocuparse del tema del mal en el ya mencionado ensayo incluido en Elogio della mitezza.

En este orden de consideraciones sobre la vigencia o no de las categorías del pensamiento, me permito recordar que, a su manera y valiéndose de las lecciones de los clásicos, Bobbio discutió en muchos textos posteriores a la publicación de “Quindici anni dopo” las relaciones entre ética y política y el tema de la razón de Estado. En los dos ensayos síntesis incluidos en Elogio della mitezza, observa Bobbio que una de las maneras de tratar esta siempre problemática relación es considerar que la afirmación no ética de la razón de Estado encuentra su justificación en la excepción a la regla, por fuerza de la necesidad, que no tiene ley sino que es ley en sí misma. Es lo que sucede en el derecho penal o en el derecho constitucional en el estado de emergencia. La doctrina de la razón de Estado afirma, así, la posibilidad de la derogación de las normas por justa causa y justifica de esta manera la contravención lícita de los gobernantes, que también se sostiene por la naturaleza especial

${ }^{7}$ L'età dei diritti, cit. p. XI; Celso Lafer, A Reconstrução dos Direitos Humanos, um diálogo com o pensamento de Hannah Arendt, cit. cap. III y IV.

${ }^{8}$ Norberto Bobbio, Quindici anni dopo, in loc. cit. p. 5. 
de la ética política como una ética especializada ${ }^{9}$. Lo que vuelve el horror del Holocausto aún más incomprensible es precisamente el hecho de no ser la consecuencia de un estado de necesidad. De ahí la perplejidad que produce, pues el repertorio del pensamiento no nos ofrece categorías para tratar el tema. Como dice Bobbio "es la límpida gratuidad de los campos de exterminio lo que me deja extraviado y me hace preguntar: ¿por qué? ¿qué sentido ha tenido todo esto?"10

Hago notar que, en su reflexión sobre el proceso Eichmann y las cuestiones jurídicas y políticas que suscitó, Hannah Arendt discute este problema en un texto de 1964, "Personal Responsibility Under Dictatorship”, sólo recientemente publicado en su versión completa. Allí señala que la clásica teoría de la razón de Estado no anticipó la completa reversión de la legalidad en el régimen nazi, pues lo que caracterizó al régimen fue la normalidad de las actividades criminales. Así, los actos criminales no son una excepción a la regla justificada por un estado de necesidad, sino la propia regla de un permanente estado de excepción. Paradójicamente, es el estado de necesidad el que puede retrasar el exterminio, como en un momento fue la decisión de Himmler, que ella menciona en este contexto ${ }^{11}$.

\section{IV}

En “Quindici anni dopo” Bobbio anticipa y aclara puntos de su posterior reflexión, incluida en Elogio della mitezza, sobre la naturaleza del prejuicio y el racismo y, más específicamente, sobre el criterio de la superioridad de una "raza” sobre otras que da a la superior "el derecho de suprimir al inferior”. De esta aberración “la más destructiva históricamente ha sido la «solución final» inventada por los nazis para resolver el problema judío en el mundo"12. Desde el punto de vista operativo esta aberración se plasmó, como señaló Hannah Arendt, en el concepto de “enemigo objetivo”, o sea, en el odio público y la lucha no contra un judío sino contra el judío en general, con independencia de la actitud o la acción de los judíos como individuos, que es característica del antisemitismo moderno por ella examinada en The

\footnotetext{
${ }^{9}$ Cf. Norberto Bobbio, Elogio della mitezza, cit. p. 67-120.

${ }^{10}$ Norberto Bobbio, Quindici anni dopo, in loc. cit. p. 5.

${ }^{11}$ Hannah Arendt, Responsibility and Judgement, edición y prólogo de Jerome Kohn, Nueva York, Schocken Books, 2003, p. 39; Giorgio Agamben entiende que el Tercer Reich puede ser considerado, del punto de vista jurídico, como un estado de excepción que duró doce años y que el totalitarismo puede ser definido como un estado de excepción instaurador de una guerra civil legal que permite la eliminación física no sólo de adversarios políticos sino de clases enteras de ciudadanos que por una razón u otra parecen no integrables en el sistema político. Cf. Giorgio Agamben, État d'Exception, París, Seuil, 2003, p. 11.

${ }^{12}$ Elogio della mitezza, cit. p. 130.
} 
Origins of Totalitarianism ${ }^{13}$. En “Quindici anni dopo” Bobbio formula en los siguientes términos el odio público del racismo antisemita, inherente al concepto de "enemigo objetivo": "el odio racial, el odio no dirigido a esta o aquella persona, sino a un «genus», y por tanto a todos los que pertecen a ese «genus», con independencia de que me hayan causado algún daño”. Seguidamente aclara, a propósito del genocidio: "Pero si esta es una explicación - y por mucho que busco me parece la única posible—- es también la más dura condena del nazismo: por la misma razón que el amor más algo es el amor no a esta o aquella persona querida, sino a mi prójimo, también el odio más bajo es el odio no al individuo sino a toda una raza, y por tanto a los individuos que pertenecen a ella, no por culpas de las que sean responsables sino por su descendencia” ${ }^{14}$.

Bobbio trata esta mancha que no se lava, los "delitos que nunca se expían del todo”, señalando que "no existen expiaciones colectivas. La expiación es siempre un hecho individual, como son individuales las faltas que la reclaman” ${ }^{15}$. En este punto, para aclarar la posición de Bobbio, me permito recurrir nuevamente al tema de la culpa y de la responsabilidad tal y como lo discutió Hannah Arendt. En sus reflexiones provocadas por el proceso Eichmann, Hannah Arendt se ocupa del tema de la culpa colectiva y en un texto de 1968 establece una diferencia -una dicotomía al modo de Bobbio- entre el sentirse culpable y la responsabilidad colectiva. La culpa (guilt) es personal, se refiere a actos y no a intenciones y posibilidades. Es esta la posición de Bobbio en un artículo de 1988, en el que a partir de Jaspers y, tratando de la Schuldfrague alemana, afirma: "No existe una culpa colectiva. La culpa colectiva, supuesto que sea lícito usar esta expresión, es siempre sólo la suma, grande o pequeña, de responsabilidades individuales”16. En cambio, la responsabilidad colectiva, señala Hannah Arendt, tiene otra característica. Es política e implica una preocupación que no va hacia el propio ser sino hacia el mundo. Tiene, de esta manera, la dimensión griega y romana de la virtud política de la ciudadanía, cuyo criterio es la buena conducta para el mundo en que se vive ${ }^{17}$.

${ }^{13}$ Cf. Celso Lafer, Hannah Arendt, Pensamento, Persuasão e Poder, $2^{\mathrm{a}}$ ed. revisada y ampliada, San Pablo, Paz e Terra, 2003, cap. 3; Pierre Ansart, Hannah Arendt: A obscuridade dos ódios públicos, in A banalização da violência: a atualidade do pensamento de Hannah Arendt, André Duarte, Christina Lopreato, Marion Brepohl de Magalhães, org. Río de Janeiro, Relume Dumará, 2004, p. 17-33.

${ }^{14}$ Norberto Bobbio, “Quindici anni dopo”, in loc. cit. p. 5.

${ }^{15}$ Norberto Bobbio, "Quindici anni dopo”, in loc. cit. p. 8.

${ }^{16}$ Cf. Norberto Bobbio, L’utopia capovolta, Turín, La Stampa, 1990, p. 125.

${ }^{17}$ Cf. Hannah Arendt, Responsibility and Judgement, cit. p. 151-153. 
Es esta republicana responsabilidad política la que, teniendo en cuenta conciencia y recuerdo, Bobbio asume en la conclusión de su texto: "Nuestro deber de afirmar que no hay razas sino hombres; que el odio racial es uno de los flagelos más terribles de la humanidad; que la expresión más violenta del odio racial ha sido el hitlerismo, compartido por la mayor parte de los «buenos patriotas» alemanes; que la aparición de una esvástica es una sombra de la muerte y que allí donde reaparezca, los hombres de buena voluntad, por divididos que estén en las ideologías y en los intereses, están comprometidos a reunirse en un pacto de solidaridad para cancelarla”18.

\section{V}

Me permito concluir este texto preparado para esta mesa redonda en homenaje a Norberto Bobbio con un hecho con una dimensión personal. Releí “Quindici anni dopo” a principios de 2003 y en él encontré aliento e inspiración cuando preparaba un dictamen como amicus curiae para el Supremo Tribunal Federal (STF) de Brasil a propósito del caso Ellwanger, en el juicio del habeas corpus 82424/RS. En el habeas corpus, este editor de Porto Alegre, de confesada orientación nazi, alegó la prescripción de la pena que se le había impuesto por el delito de práctica de racismo, por su conducta sistemática de instigación al odio racial mediante la publicación de obras antisemitas, por la denegación del hecho histórico del Holocausto y por la apología del nazismo. Recuerdo que el revisionismo de Ellwanger es del tipo que Bobbio califica, en un artículo de 1996, como negativo, “que niega, por espíritu de parte, hechos comprobados”, haciendo alusión a los "historiadores” como Faurisson para los que se acuñó la categoría de revisionismo ${ }^{19}$.

En este leading case, el STF concluyó el proceso del habeas corpus en septiembre de 2003 y, por una clara mayoría de ocho votos, confirmó la condena de Ellwanger por el crimen de práctica de racismo. Tanto en el dictamen como en varios artículos que escribí sobre el tema y en conferencias y entrevistas dadas, recurrí a la Convención para la prevención y la represión del crimen de genocidio y a la Convención para la eliminación de todas las formas de discriminación racial, cuya importancia Bobbio subraya en L'età dei diritti. Me serví también, y mucho, de la obra de Bobbio, sobre todo de L'età dei diritti y de Elogio della mitezza, y cabe señalar que los Ministros del STF hicieron innumerables referencias a Bobbio en sus fundamentaciones, lo que indica la repercusión de la recepción de su obra en Brasil. Fue lo que le relaté a Bobbio en una carta del 20 de octubre de 2003, junto con

\footnotetext{
${ }^{18}$ Norberto Bobbio, Quindici anni dopo, in loc. cit. p. 9.

${ }^{19}$ Norberto Bobbio, Il dubbio e la ragione, Turín, La Stampa, 2004, p. 85.
} 
la cual le envié el artículo, publicado en O Estado de S.Paulo del 19 de octubre de 2003, en el que celebré sus 94 años con afectuosa admiración. Fue también esto lo que tuve la oportunidad de decirle, de viva voz, el 30 de noviembre, cuando lo visité por última vez en Turín, pues la solución del caso Ellwanger por parte del STF, apoyada en el Derecho, obedeció, en Brasil, a la recomendación de Bobbio sobre la esvástica como una sombra de la muerte que toca a los hombres de buena voluntad borrar en un pacto de solidaridad.

De ahí, pienso yo, la pertinencia de la discusión de "Quindici anni dopo" en esta mesa redonda, pues se trata de rescatar la importancia de uno de sus textos menos conocidos y de más difícil acceso. Creo que Bobbio apreciaría este rescate en esta celebración en su homenaje, pues "Quindici anni dopo" está en consonancia con su sensibilidad sobre el tema. En efecto, en un texto de 1978, Bobbio recuerda su juventud en Turín, su amistad con compañeros judíos y su relación con Leone Ginzburg a quien consideraba un hermano mayor y afirma: "Fue esta proximidad, ésta que he llamado afinidad electiva, a mis coetáneos la que me hizo sentir con particular intensidad, con una sensibilidad casi morbosa, la infamia de la gran hecatombe de la que los judíos fueron víctimas durante la sangrienta dominación de Hitler en Europa”" ${ }^{20}$.

(Trad. de Luisa Juanatey)

${ }^{20}$ Ebrei di ieri e ebrei di oggi fronte al fascismo, Il Ponte-XXXIV n ${ }^{\circ} 11-12,30$ noviembre31 diciembre 1978, p. 1314-1318. 
$\triangle \quad$ DOXA 28 (2005) 